\title{
Number of Garment Sample Require for Readymade Garment (RMG) Sector
}

\author{
Md. Tabraz ${ }^{1}$, Kamrun Nahar Naznin ${ }^{2}$ \\ Lecturer, Fashion Design Department, BGMEA University of Fashion \&Technology (BUFT), Dhaka, Bangladesh
}

\begin{abstract}
In Bangladesh, the RMG sector has experienced an exponential growth since the 1980s. There were only 50 factories employing only a few thousand people. Currently, there are approximate 6000 manufacturing units. Owing to the emergence of strong backward linkages within the country, the Knitwear Industry is adding up to $80 \%$ value, which opens up enormous potential for foreign and domestic investors to spend in the areas of spinning, weaving, sewing, packaging, and accessories manufacturing. Apart from that, every industry has to face huge competition to execute orders. Still most of the factories are struggling to survive this competition race. On manufacturing process garments sample play an important role for receiving a garments export order. Sample section of garments manufacturing factory has done this job. As a result, among all the others section like as cutting, sewing, finishing etc. sample section gets the maximum priority in demands. In this article mainly discuss about the number of sample needed in readymade garments industry.
\end{abstract}

Keywords: manufacturing units, backward linkages, domestic investors, spinning

\section{Introduction}

Garment sampling is very much important process. It is a model of what the bulk production is going to be done. The sampling is quite difficult but it will make the buyers to get attractiveness towards the industry. Because the buyers generally places the order after they are satisfied with the quality of the samples. Garment sampling is a very important task in an apparel manufacturing because it gives the satisfaction of the customer with respect to the product being manufactured. This is in turn important because if the buyer is not satisfied by the samples, this puts the following at risk:

- Placement of the order

- Acceptance of the some or the entire quantity of garments produced.

There may be a separate sampling department in a company. But as the merchandiser is the person who is interacting with the buyers regarding samples and other requirements, this sampling department will work under the guidance Also as the samples are to be made according to the buyers' price ranges and quality levels, merchandiser has to advise.

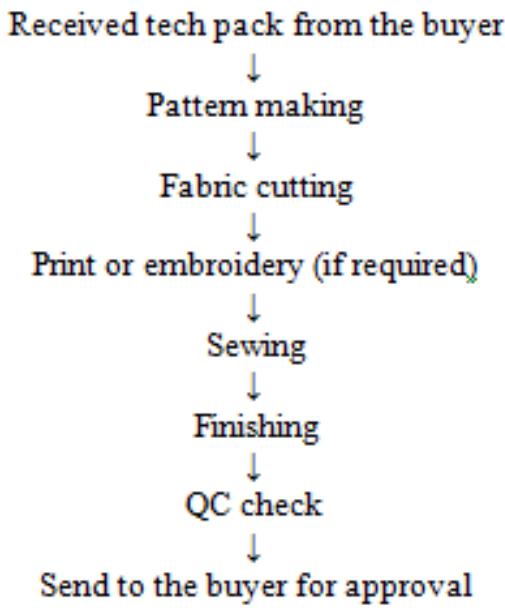

Figure 1: Process Sequence of Garments Sample Making
There are many reasons why it's recommended to make multiple samples; some reasons are given below-

- To see how design or sketch looks practically

- To placement of order

- Acceptance of the some or the entire quantity of garments produced

- To fit test and check measurements is correct or not

- To allow the buyer to judge the production capabilities of the manufacturer

- To provide a means for making revisions in the bulk production process

- To let the manufacturer estimate the thread and fabric consumption, and develop cost quotations

There are different phases of sampling; the first phase covers the development of the initial concept or design idea and getting the approval by the customer. The second phase covers the process after getting acceptance of the first prototype sample and carry out the functions of sourcing and ordering component, testing the product and carry out trails once the finalized sample specifications has been drawn up. The third and final phase includes a range of activities that are carried out before large scale or bulk production capacity outside the producer/developers if this is needed.

\section{Effective Sample Types}

We have to send many samples to buyers. We are trying to shout out one procedure which is effective sample types listed below -

1) Development sample

2) Proto Sample or Fit Sample

3) Revised Fit Sample

4) Photo Shoot Sample

5) Salesmen Sample/Promotional Sample

6) Size Set Samples

7) Wearing Test Sample

8) Wash Test Sample

9) Pre Production Sample

10) Production sample/Counter Sample/Reference Sample

11) Shipment Sample

Volume 6 Issue 7, July 2017 


\section{International Journal of Science and Research (IJSR) \\ ISSN (Online): 2319-7064 \\ Index Copernicus Value (2015): 78.96 | Impact Factor (2015): 6.391}

a) Development Sample:

This is the first sample of any design. Actually this is visualizing an idea in three-dimensional from. It made by available fabric \& accessories and sends to buyer to collect order is called development sample. Buyers first time give tech patch or PDM to vendors just for making pattern and samples as per sketch. Sometimes it is called LA sample. Buyers just need to review the style or the design to make changes in this sample where fabric will actual but other trims may not be actual.

b) Proto Sample or Fit Sample:

These samples are making after getting the new order from buyer and after confirmation of development sample. This sample is made to check the fit of the particular style. This sample can make with available similar fabrics, fiber, nearer GSM and any color, if actual fabric is not available that time. This sample made by the exporter based on the original sample or sketch and specification sheet given by the buyer. Ideally, a proto sample is also sewing by as described below. If you sew in house, the prototype should be used for costing and become the production sew-by. After sending the proto or Fit samples the buyers will conduct discussion over the samples and they will access the content of the sample and give us comment and reviews.

c) Revised Fit Sample

After getting review comments of fit sample, need to make fit sample again which is called revised fit sample. This sample also made to check the fit of the particular style. This sample can make with available similar fabrics, fiber, nearer GSM and any color, if actual fabric is not available that time. It's also send to buyer and they give us comments for next sample.

d) Photo Shoot Sample

Photo Shoot Sample is made for photo shoot. Samples are made to the size of model as it is using for product photography. If you aren't using a model for your look book or e-commerce imagery, it is still recommended that you have smaller size photo samples that can fit into frame of the camera.

e) Salesmen Sample/Promotional Sample

As a business to business company provide complimentary samples to clients and prospective customers to assist them with evaluating the quality of custom printed promotional products. Ideally, the preproduction sample above can be used for sales and marketing. You would have duplicates of the approved pre-production or production sample made for each party.

f) Size Set Samples

These are full set of sample which size is requiring on measurement chart given by buyer. Sample made to ensure appropriate grading of the style and the fit of each garment. One way to save a bit of money, in fabric and trimming as well as cut and sew costs would be to produce every other size. Buyer check those sample fittings and every single design as size wise printing and others accessories also be changed some time. If there have any comments from buyer on this sample exporter can modify those on Pre production sample

g) Wearing Test Sample

Mainly this sample makes for Sweater item. This sample makes with all actual fabric for wearing test. This is not buyers' main concern as any other sample but sometimes they want. It makes to check that garments are wearable, comfort and pilling can happens or not on surface and so on.

h) Wash Test Sample

This sample should be sent to the suppliers before starting their production. In house wash test is doing by using this sample. By this test actually buyer checks the shrinkage percentage, elongation ratio, pilling, and spirality and so on. This is last and final wash test check by suppliers before production start. If find out any problem on this test, it treatment again before production start.

\section{i) Pre-Production Sample}

After size set approval need to make Pre Production Sample, in short from it is called PP sample. It is the ideal sample for production. This sample has to make with actual production fabric with actual trims. Actually this sample is like mirror of final production. Garments folding, label placement, poly packing needs to check and need to get okay confirmation with this sample otherwise factory cannot start bulk production. After the buyer has inspected the sample, a pre-production meeting is called. In this meeting buyer or his agent, merchandiser, sample manager, all remain present. They decide on how and when to start the production. If the decision Okay, the sample is ready to go for final production.

\section{j) Production sample/Counter Sample/Reference} Sample

This set of samples is taken off the line during your first production order. The number of Top of production (TOP) sample you receive is typically a percentage of the full production order in each variation, but this can get expensive. One way to save costs would be to keep your TOP percentage very low. For small batch orders, one or two garments per variation should suffice.

k) Shipment Sample/Gold Seal Sample

The gold seal or shipment sample seems production sample and it is representative of the bulk. Sample is taken from production, complete with labeling and hangers. After approval of this sample supplier can deliver the goods. This sample must be received minimum of 10 days prior to delivery.

\section{Discussion}

A perfect sample helps highest possibility to collect orders from buyers. Here mentioned different types of sample for the garment industry but not necessary to make all samples. What types of Sample need to make depends on buyers' requirements. It is good for the manufacturer to prepare garments costing, if they (buyer) provide complete list of name and required number sample. Normally buyer provides sample making cost or buyer suggest adding sample making cost on total order pricing. From list of sample types some sample has to prepare for the buyers all time before starting production. Such as- development sample, fit sample, size set sample \& Pre-production sample. Sample helps to find out problem on pattern and also helps to understand that this design works or not. Mainly, it always plays important role to check the actual fit of garments.

\section{Volume 6 Issue 7, July 2017 www.ijsr.net}




\section{International Journal of Science and Research (IJSR) \\ ISSN (Online): 2319-7064}

Index Copernicus Value (2015): 78.96 | Impact Factor (2015): 6.391

\section{Conclusion}

Sample always a big concern for garments industry. It relates to all departments activities in industry, like order collect to shipment deliver to the buy. In a short, Sample section is a heart of RMG industry. It ensures orders and helps to survive in money making competition race. Still most of the industries do not know exact number of sample require for the buyers, as results every year a good number of industries shut down their garments business lack of executing orders. This paper will provide good knowledge about the list of sample prepare for the vendor in readymade garment industry.

\section{Acknowledgement}

I would like to extend my deepest gratitude towards my colleagues, BGMEA university of Fashion and Technology, Dhaka, Bangladesh. I am highly acknowledged to my co-author for consistent support and guidance in correct direction. Without his proactive support I could not write this article.

\section{References}

[1] http://www.hofsuppliers.co.uk/info/pdf/SM_QA_Access ories.pdf

[2] http://txvicky.blogspot.com/

[3] http://www.garmentsmerchandising.com/process-flowchart-of-garments-sample-making/

[4] http://fashion-incubator.com/the-13-different-kinds-ofsamples/

[5] https://apparelbrief.wordpress.com/2012/05/16/differenttype-of-sample-with-defination/

Volume 6 Issue 7, July 2017 www.ijsr.net 